\title{
Mapping of QTLs for lateral and axile root growth of tropical maize
}

\section{Journal Article}

\section{Author(s):}

Trachsel, Samuel; Messmer, Rainer; Stamp, Peter; Hund, Andreas (D)

Publication date:

2009-11

Permanent link:

https://doi.org/10.3929/ethz-b-000021406

\section{Rights / license:}

In Copyright - Non-Commercial Use Permitted

\section{Originally published in:}

Theoretical and Applied Genetics 119(8), https://doi.org/10.1007/s00122-009-1144-9 


\title{
Mapping of QTLs for lateral and axile root growth of tropical maize
}

\author{
Samuel Trachsel - Rainer Messmer • \\ Peter Stamp · Andreas Hund
}

Received: 1 January 2009/Accepted: 21 August 2009/Published online: 17 September 2009

(C) Springer-Verlag 2009

\begin{abstract}
Maize genotypes may adapt to dry environments by avoiding desiccation by means of a deeper root system or by maintaining growth and water extraction at low water potentials. The aim of this study was to determine the quantitative genetic control of root growth and root morphology in a population of 236 recombinant inbred lines (RILs) from the cross between CML444 (highyielding) $\times$ SC-Malawi (low-yielding), which segregates for the response to drought stress at flowering. The RILs and the parental lines were grown on blotting paper in growth pouches until the two-leaf stage under non-stressed conditions; the parents were additionally exposed to desiccation stress induced by polyethylene glycol with a molecular weight of 8000 Dalton (PEG-8000). The lengths of axile and lateral roots were measured non-destructively at 2, 5, 7 and 9 days after germination, by scanning with an A4 scanner followed by digital image analysis. CML444 had a lower rate constant of lateral root elongation $\left(\mathrm{k}_{\mathrm{Lat}}\right)$ than SC-Malawi, but the two genotypes did not differ in their response to desiccation. QTLs affecting root vigor, as depicted by increments in $\mathrm{k}_{\mathrm{Lat}}$, the elongation rate of axile roots $\left(\mathrm{ER}_{\mathrm{Ax}}\right)$ and the number of axile roots $\left(\mathrm{No}_{\mathrm{Ax}}\right)$ were identified in bins 2.04 and 2.05. QTLs for $\mathrm{No}_{\mathrm{Ax}}$ and $\mathrm{ER}_{\mathrm{Ax}}$ collocated with QTLs for yield parameters in bins 1.031.04 and 7.03-04. The correspondence of QTLs for axile root traits in bins 1.02-1.03 and 1.08 and QTLs for lateral
\end{abstract}

Communicated by $\mathrm{Y} . \mathrm{Xu}$.

S. Trachsel $\cdot$ R. Messmer $\cdot$ P. Stamp $\cdot$ A. Hund $(\square)$

Institute of Plant Science, ETH Zurich, Andreas Hund,

Universitaetstr. 2, 8092 Zurich, Switzerland

e-mail: andreas.hund@ipw.agrl.ethz.ch

S. Trachsel

e-mail: samuel.trachsel@ipw.agrl.ethz.ch roots traits in bins 2.04-2.07 in several mapping populations suggests the presence of genes controlling root growth in a wide range of genetic backgrounds.

\section{Introduction}

In order to cope with dry environmental conditions plants have evolved different strategies such as the avoidance of and tolerance to desiccation. Desiccation avoidance is associated with the minimization of water loss and the maximization of water uptake (Ludlow and Muchow 1990). Water uptake in drying soils can be improved by optimizing access to water-bearing soil layers. For the individual plant, drought will be most successfully avoided when changes in carbon allocation patterns result in the formation of a deep root system before the onset of a growth-limiting water shortage (Fischer and Turner 1978; Blum 1985; Campos et al. 2004). Improvements of root distribution in the soil (Price et al. 2002), root length density and root hydraulic conductivity (Steudle 2000) are important factors, which determine grain yield in droughtprone environments.

Several authors found genotypic variation for rooting depth in maize: Two drought-tolerant maize hybrids had 2.3-3.3 times more axile roots (referred to as primary roots) in deep moist soil layers than a drought-sensitive hybrid (Wan et al. 2000) when grown in soil pots. The maize hybrid Pioneer-3165, with a deeper root profile, wilted later under drought than Pioneer-3192 (Lorens et al. 1987). Hund et al. (2009a) reported greater rooting depth of the high-yielding subtropical line CML444 compared to the lower-yielding line SC-Malawi. This difference was associated with a greater extraction of water from deep soil layers in the case of CML444. 
Many traits that are related to the water status of the plant may be affected by deeper rooting in drought-prone environments. A drought-tolerant ideotype with improved morphology can be defined, according to Ribaut et al. (2008), as a plant with smaller tassels, smaller leaves above the ear, erect leaves, a larger stem diameter, stay-green and deeper rooting with less lateral branching and less root biomass. Avoiding water loss by smaller leaves in combination with an increased uptake of water and nitrogen due to deeper root systems enhances the avoidance of desiccation during drought periods. This in turn may allow the plant to maintain organ growth and functioning, leading to a narrow anthesis-silking interval (ASI) and to reduced senescence. A narrow ASI (i.e. the synchrony between male and female flowering time) has been an important trait for improving drought tolerance of maize (Edmeades et al. 1999). Desiccation stress during flowering slows down ear and silk growth and delays silk emergence (Fuad-Hassan et al. 2008), leading to reduced kernel set due to a wider ASI. Reduced or delayed plant senescence, which is also referred to as staygreen, is in parts a consequence of a sufficient uptake of $\mathrm{N}$ and water (Rajcan and Tollenaar 1999) and may be related to a deep root system with higher uptake rates (Gallais and Hirel 2004). Leaf longevity and the duration of grain filling are both extended in stay-green genotypes (Paponov et al. 2005), thereby increasing the weight per kernel (Wang et al. 1999). These examples illustrate how important the architecture of the root system might be for the response of maize to water-limited conditions in the field.

However, root morphology and architecture are usually not directly accessible for breeders. The obvious reason is that roots located in the soil cannot be assessed with current methodologies. QTL analysis in combination with proteome and transcriptome analysis have revealed insights into the genetic basis of root architecture affecting crop yield under different water regimes (Hochholdinger and Tuberosa 2009). The detection of quantitative trait loci (QTLs) for root traits offers marker-assisted selection (MAS) as an alternative approach to destructive root sampling. Markerassisted backcross selection has been applied to increase root length and diameter in Indian upland rice varieties by the introgression of four unlinked QTLs (Steele et al. 2006). Shen et al. (2001) transferred Azucena alleles to IR64 in rice for deeper roots. Furthermore, Ribaut and Ragot (2007) used MAS to introgress favorable alleles for yield and flowering traits in five target regions in tropical maize. QTLs for root traits (Tuberosa et al. 2002 and references therein) as well as their response to drought (Lebreton et al. 1995), low phosphorous (Zhu et al. 2005a, b), low nitrogen availability (Gallais and Hirel 2004; Liu et al. 2008) and cold stress (Hund et al. 2004) have been identified. Tuberosa et al. (2002) and Liu et al. (2008) observed collocating QTLs between root morphology at the seedling stage, traits related to drought tolerance in the field and grain yield, which indicates the relevance of root morphology at the seedling stage for plant establishment and performance at later stages.

Preliminary experiments revealed that the tropical maize line CML444 produced more axile than lateral roots in growth pouches relative to SC-Malawi. It may be postulated, that this relative increase of axile roots led to deeper rooting of CML444 at later stages of development as shown by Hund et al. (2009a). Growth pouches, consisting of a piece of blotting paper covered with opaque plastic film, are suited to identify QTLs controlling root morphology at an early seedling stage. Upon validation of these QTLs with results obtained during later stages of development, the pouch system could be used as tool to predict the development of the root system of maize genotypes. Moreover, desiccation stress can easily be applied in growth pouches by varying concentrations of PEG-8000, an osmolyte that lowers the water potential of the substrate (Lawlor 1970; Money 1989; Oertli 1985; van der Weele et al. 2000, Nayyar and Gupta 2006; Sanguineti et al. 2006). This makes it possible to assess the response to desiccation in the pouch system, besides measuring constitutive differences in the development of the root system among genotypes.

The objectives of this study were to (1) evaluate the root development of CML444 and SC-Malawi under wellwatered and water-stressed conditions induced with PEG8000, (2) identify QTLs for root traits at the juvenile stage and after successful identification, (3) compare these QTLs with QTLs previously identified in the reproductive stage under field conditions (Messmer 2006; Messmer et al. 2009).

\section{Materials and methods}

\section{Plant material}

Two tropical maize inbred lines and 236 recombinant inbred lines (RILs, F7:S6) were used. The parental line CML444 is much alike the ideotype of a drought tolerant maize line described by Ribaut et al. (2008). It has been developed at CIMMYT during the 1990s, selected for a short ASI, and is among the most drought-resistant CIMMYT germplasm. SC-Malawi is an old inbred line developed in Zimbabwe in the 1960s. Compared to CML444, SC-Malawi has a low yield under stress and nonstress conditions (Messmer et al. 2009).

\section{Growth conditions}

Seeds were surface sterilized with $2.5 \% \mathrm{NaOCl}$ solution. Upon germination seeds with equal root lengths were 
transferred to the moistened blotting paper (Anchor Paper, St. Paul, MN, USA) which was placed in growth pouches $(21 \mathrm{~cm} \times 30 \mathrm{~cm})$, as described by Hund et al. (2009b).

In the desiccation stress experiment, pouches were placed upright into plastic containers $(27 \mathrm{~cm}$ wide $\times$ $37 \mathrm{~cm}$ long $\times 32 \mathrm{~cm} \mathrm{high)} \mathrm{containing} 41$ of a modified Hoagland solution $\left(5 \mathrm{mM} \mathrm{KNO}_{3}, \quad 5 \mathrm{mM} \mathrm{Ca}\left(\mathrm{NO}_{3}\right)_{2}\right.$, $2 \mathrm{mM} \mathrm{MgSO}_{4}, 1 \mathrm{mM} \mathrm{KH} \mathrm{PO}_{4}$ ), so that the lowest $2 \mathrm{~cm}$ of the pouches were immersed in the nutrient solution. At 3 days after germination (DAG) the nutrient solution was removed. The plants were then subjected to optimal water availability (0\% PEG), a mild (15\% PEG) or a severe desiccation stress (20\% PEG) treatment. The severity of desiccation stress was quantified by measuring the predawn water potential (WP) on the mesocotyl $5 \mathrm{~mm}$ above the seed using a Scholander pressure chamber (Plant Water Status Console 3000, Soil Moisture Equipment Corporation, Santa Barbara, CA, USA) according to Scholander et al. (1965). Plants grown under well-watered conditions had a WP of $-0.14 \mathrm{MPa}$, while the application of desiccation stress resulted in a significantly lower WP of -0.40 (15\% PEG) and $-0.60 \mathrm{MPa}$ (20\% PEG). To allow the water contained in the pouch to get into equilibrium with the PEG solution, the pouches were immersed in PEG solution for $20 \mathrm{~min}$ on the first day of the PEG treatment. Pouches were subsequently immersed on a regular basis, to compensate for water losses. The daily immersions were limited to $5 \mathrm{~min}$ in order to avoid problems with the oxygen supply of the root system. All the same, the pouches were continuously moist.

In the QTL mapping experiment the pouches were placed in containers $(132 \mathrm{~cm}$ long $\times 37 \mathrm{~cm}$ wide $\times 32 \mathrm{~cm}$ high) so that the lowest $2 \mathrm{~cm}$ of the pouches were immersed in 151 of the modified Hoagland solution. The containers were placed in a growth chamber (PGW36 Conviron, Winnipeg, MB, Canada) at a temperature of $27^{\circ} \mathrm{C}$ at the seed level, a relative humidity of $70 \%$ and a photosynthetically active radiation of $400 \mathrm{~mol} \mathrm{~s}^{-1}$ per $\mathrm{m}^{2}$ at a photoperiod of $12 \mathrm{~h}$. In order to minimize heating due to light radiation, the containers were covered with aluminum laminated styrofoam, leaving a $2 \mathrm{~cm}$ wide opening at the seedlings position. At harvest leaf area was measured using a Li-3000A (LI-COR Biosciences, Lincoln, NE, USA).

\section{Root measurements}

Roots growing on the surface of the germination blotter were measured non-destructively by scanning with a Hewlett Packard Scanjet 4670 "See Thru Scanner" (Hewlett-Packard, Palo Alto, CA, USA). The pouches were scanned 2, 5, 7 and 9 days after germination (DAG). The acquired 24-bit jpeg images were processed in Adobe
Photoshop 7.0 in three steps (Adobe Systems Inc., San Jose, CA, USA) as described by Hund et al. (2009b). In the first step the saturation channel was used to obtain 8-bit images, with enhanced contrast between the roots and the background. In the second step a median filter, with a radius of three pixels, was used to remove image noise, which would have resulted in the detection of spurious roots in WinRHIZO 2003b (Regent instruments, Montreal, QC, Canada). In the third step, a threshold of 120 was applied to the tonal value to obtain binary images. These images were then analyzed by means of WinRHIZO. Seventy-two root diameter-width classes were defined, ranging from $42.33 \mu \mathrm{m}$ (1 pixel) to $3.05 \mathrm{~mm}$ (72 pixels). The debris removal filter removed objects with an area smaller than $0.02 \mathrm{~cm}^{2}$ and a length/width ratio below five. The lengths of axile and lateral roots were extracted from the root length-in-diameter class distribution obtained by WinRHIZO. Roots with diameters below $0.546 \mathrm{~mm}$ were treated as lateral roots, those with diameters above $0.546 \mathrm{~mm}$ as axile roots.

Axile and lateral roots seemed to elongate at constant rates up to the destructive harvest. Root elongation was modeled according to the elongation patterns (Fig. 1a, b) using either an exponential or a linear growth function for lateral and axile roots, respectively. Therefore, the increase in the axile root length was modeled according to:

$x(t)=x\left(t_{0}\right)+\mathrm{ER}_{\mathrm{Ax}} t ; \quad \mathrm{ER}_{\mathrm{Ax}}=\frac{x(t)-x\left(t_{0}\right)}{t}$

where $x(t)$ is the root length at time $t$ after germination, $x\left(t_{0}\right)$ is the root length at the first day of scanning (DAG 3 ) and $\mathrm{ER}_{\mathrm{Ax}}$ represents the daily elongation rate. The increase in the lateral root length was modeled as:

$x(t)=x\left(t_{0}\right) \times e^{\mathrm{k}_{\mathrm{Lat}}} ; \quad \mathrm{k}_{\mathrm{Lat}}=\frac{\log (x(t))-\log \left(x\left(t_{0}\right)\right)}{t}$

where $\mathrm{k}_{\mathrm{Lat}}$ is the rate constant for lateral root elongation. The mean $R^{2}$ of each fitted model (see Fig. 2) was extracted and used to identify plants with a bad model fit ( $R^{2}$ below 0.8 ). These plots were evaluated separately and problematic images were eventually eliminated from the analysis ( 3 images based on low $R^{2}$ for $\mathrm{k}_{\mathrm{Lat}}$ and 1 based on a low $R^{2}$ value for $\mathrm{ER}_{\mathrm{Ax}}$ ). In order to obtain a measure of the increase of lateral root length per unit increase of axile root length, the ratio between $\mathrm{k}_{\mathrm{Lat}}$ and $\mathrm{ER}_{\mathrm{Ax}}$ was calculated $\left(\mathrm{k}_{\mathrm{Lat}} / \mathrm{ER}_{\mathrm{Ax}}\right)$.

The plants were harvested ten DAG. The dry weight of the shoots (SDW) and roots (RDW) was determined after drying for $72 \mathrm{~h}$ at $65^{\circ} \mathrm{C}$. The length of the primary axile root $\left(\mathrm{L}_{\mathrm{PrAx}}\right)$ was measured digitally in images acquired nine DAG using the ruler tool in Photoshop. The number of axile roots $\left(\mathrm{No}_{\mathrm{Ax}}\right)$ was counted manually on nine DAG. 
Fig. 1 Mean values of lateral root length (a) and axile root length $(\mathbf{b})$ of the

CML444 × SC-Malawi population non-invasively measured 2, 5, 7 and 9 days after germination. Error bars represent $1 \mathrm{SE}$

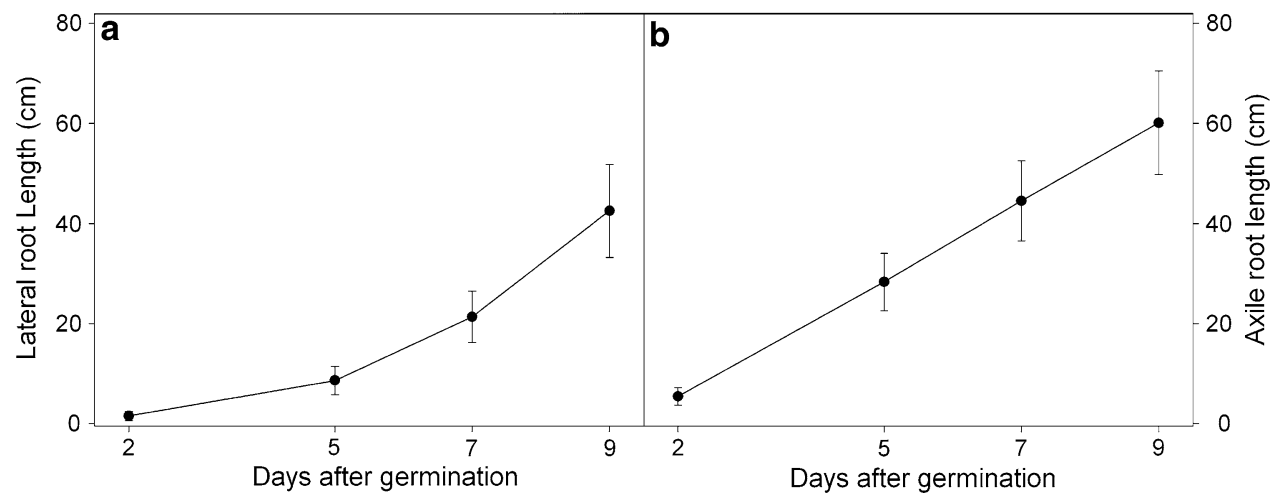

Fig. 2 Frequency distribution of the coefficients of determination $\left(R^{2}\right)$ of model 1 (a) and model 2 (b), fitted to the development of each individual plant, to estimate the elongations rates of lateral $\left(\mathrm{k}_{\mathrm{Lat}}\right)$ and axile $\left(\mathrm{E}_{\mathrm{RAx}}\right)$ roots, respectively

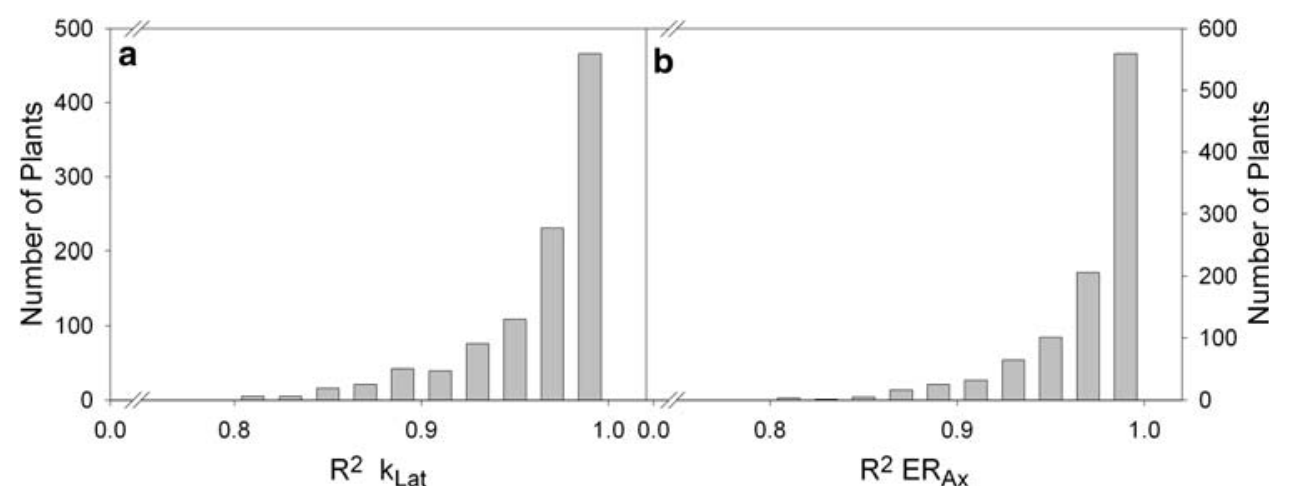

\section{Experimental design and statistics}

\section{Desiccation stress experiment}

The desiccation stress experiment was carried out with the parental lines only. These were evaluated in six consecutive growth chamber runs $\left(r_{k}, k=1, \ldots, 6\right)$, each containing two desiccation stress treatments (15 and 20\% PEG) and a non-stressed control treatment (without PEG). Each treatment contained one plant of either line, resulting in a total of six plants per genotype and treatment. The phenotypic data was analyzed with the linear mixedeffect model

$Y_{i j k}=\mu+\alpha_{i}+\beta_{j}+(\alpha \beta)_{i j}+r_{k}+(r \beta)_{k j}+\varepsilon_{i j k}$

where $Y_{i j k}$ is the trait value of genotype $i$ in treatment $j$ within growth chamber run $k, \alpha \beta$ is the genotype-by-treatment interaction, $r \beta$ the growth chamber run-by-treatment interaction, and $\varepsilon$ the residual error. All effects were fixed, except for $r, r \beta$ and $\varepsilon$.

Analysis of variance was performed using the GLM procedure in NCSS (Number Cruncher System, Kayesville, UT, USA). Comparisons among treatment levels and among genotypes were carried out using the TukeyKramer multiple comparison test.
QTL mapping experiment

The experiment was designed as an alpha lattice $(0,1)$ with six independent replications $\left(r_{j}\right), 240$ genotypes $\left(g_{i} ; 236\right.$ RILs and $2 \times 2$ parents) and 12 plots per incomplete block $\left(p_{j k l}\right)$. The 20 incomplete blocks were distributed in five growth containers $\left(b_{j k} ; 132 \mathrm{~cm} \times 32 \mathrm{~cm} 5 \mathrm{~cm}\right)$ in a growth chamber. The effects of the replication were considered to be fixed, while genotypes, containers and incomplete blocks were random.

Accordingly, the mixed linear model was:

$Y_{i j k l}=\mu+r_{j}+g_{i}+b_{j k}+p_{j k l}+\varepsilon_{i j k l}$

where $Y_{i j k l}$ is the effect of genotype $i$ in growth chamber run $j$, growth container $k$ and incomplete block $l$, and $\varepsilon$ is the residual error.

Analysis of variance was carried out with the ASReml-R package (Butler 2006), and the best linear unbiased predictors (BLUPs) were extracted and used as the input values for QTL mapping. The broad-sense heritability of each trait was calculated as:

$h^{2}=\frac{\sigma_{g}^{2}}{\sigma_{g}^{2}+\frac{1}{j} \sigma_{\varepsilon}^{2}}$

where $\sigma_{\mathrm{g}}^{2}$ is the genetic variance, $\sigma_{\varepsilon}^{2}$ the residual error variance and $j$ the number of replications. 
Phenotypic Pearson's correlations between pairs of traits were estimated using the function cor.test() in $\mathrm{R}$ ( $\mathrm{R}$ Development Core Team 2004). Significant correlations with $\quad 0.2 \leq r^{2} \leq 0.5, \quad 0.5<r^{2} \leq 0.8, \quad 0.8<r^{2}$, were defined as weak, moderate and strong, respectively.

QTL analysis

QTLs were identified by composite interval mapping (CIM) using QTL cartographer 1.17 (Basten et al. 2002) based on genetic information from the linkage map published in Messmer et al. (2009). Co-factors were selected by forward and backward regression with the in and out values set at 0.05 and 0.1 , respectively. In zmapqtl a walking speed of $2 \mathrm{cM}$ was selected. The number of background parameters was set to 5. QTLs were estimated on the basis of the BLUPs and a LOD threshold of 2.6. Assuming that each chromosome arm segregates independently, the corresponding experimental Type- $I$ error probability $\left(\alpha^{\prime}\right)$ was approximately 0.05 .

QTLs for different traits collocated when their LODsupport intervals overlapped, which were defined as the intervals on the chromosome in which the LOD at the peak decreased by half. A collocation was considered to be positive when the additive effects had the same algebraic sign and negative when they had opposed algebraic signs.

\section{Results}

\section{Desiccation stress}

The desiccation treatment significantly affected $\mathrm{k}_{\mathrm{Lat}}, \mathrm{ER}_{\mathrm{Ax}}$, RDW, WP and leaf area. CML444 and SC-Malawi significantly differed for $\mathrm{k}_{\mathrm{Lat}}$, WP and leaf area (Table 1). No significant desiccation-by-genotype interactions were identified. In response to the highest desiccation level, $\mathrm{k}_{\mathrm{Lat}}$ and $\mathrm{ER}_{\mathrm{Ax}}$ were reduced by 20 and $32 \%$. By contrast, $\mathrm{L}_{\operatorname{PrAx}}$ and $\mathrm{No}_{\mathrm{Ax}}$ were not altered in response to desiccation. In accordance with reductions in root elongation, RDW was reduced by 19 and $50 \%$ at the moderate and the severe desiccation stress level, respectively. With respect to shoot traits both WP $(-65 \% ;-74 \%)$ and leaf area $(-44 \%$; $-55 \%$ ) were reduced at the 15 and $20 \%$ PEG treatment, respectively. The application of desiccation stress resulted in similar responses for both CML444 and SC-Malawi, none being more tolerant to the PEG-induced desiccation stress. However, irrespective of the PEG treatment the genotypes differed for $\mathrm{k}_{\mathrm{Lat}}$, WP and leaf area. The obtained data strongly suggest that SC-Malawi formed more lateral roots (data not shown) resulting in higher $\mathrm{k}_{\mathrm{Lat}}(+20 \%)$ than CML444. SC-Malawi also formed a larger leaf area
$(+25 \%)$. Since the genotypes did not differentially respond to the desiccation treatment, we concluded that constitutive differences in root morphology were of greater importance than adaptive mechanisms in response to desiccation stress. The evaluation of the RILs was therefore carried out under control conditions only.

\section{QTL experiment}

\section{Differences in root traits}

Within the RIL population the axile roots grew linearly (Fig. 1b), while lateral roots grew exponentially (Fig. 1a). The coefficients of determination $\left(R^{2}\right)$ of the model fitted for each RIL individually ranged from 0.78 to 0.99 for the linear $\mathrm{ER}_{\mathrm{Ax}}$ and from 0.69 to 0.99 for the exponential $\mathrm{k}_{\text {Lat }}$, with average values of 0.96 and 0.97 per RIL (Fig. 2).

The results from the QTL experiment were similar to those obtained in the desiccation stress experiment: CML444 formed a root system with a lower proportion of lateral roots than SC-Malawi, indicated by a lower $\mathrm{k}_{\mathrm{Lat}} /$ $\mathrm{ER}_{\mathrm{Ax}}$ (Table 2). This low ratio was a result of both a significantly lower $\mathrm{k}_{\mathrm{Lat}}(-12 \%)$ and a non-significant but markedly higher $\mathrm{ER}_{\mathrm{Ax}}(+24 \%)$ of CML444.

The growth constant of the lateral roots, which was determined in the RIL population, had an interquartile range (IQR) between 0.363 and $0.413 \mathrm{~cm} \mathrm{day}^{-1}$ and a heritability of 0.73 , whereas $\mathrm{ER}_{\mathrm{Ax}}$ had an IQR between $6.72-9.40 \mathrm{~cm} \mathrm{day}^{-1}$ and a heritability of 0.8 . As a result, the ratio between $\mathrm{k}_{\mathrm{Lat}}$ and $\mathrm{ER}_{\mathrm{Ax}}$ had an IQR between 0.0416 and 0.0569 . The heritability of this ratio was 0.83 . Similar heritabilities were obtained for RDW (0.87) and leaf area (0.84).

There was a weak positive correlation between HKW and each of the following traits: $\mathrm{No}_{\mathrm{Ax}}, \mathrm{ER}_{\mathrm{Ax}}$, the length of the axile root $\left(\mathrm{L}_{\mathrm{Ax}}\right)$ and leaf area, indicating that the growth of the seedling was affected by seed reserves (Table 3). With regard to root morphological traits, we observed a typical covariance among the hierarchically dependent root traits. Since $\mathrm{ER}_{\mathrm{Ax}}$ estimates the overall growth rate of all the axile roots, a strong positive correlation was found with the number of axile roots; since the lateral roots emerged from the mother axile root, $\mathrm{k}_{\mathrm{Lat}}$ showed a weak positive correlation with $\mathrm{ER}_{\mathrm{Ax}}$. Similarly, the ratio between $\mathrm{k}_{\mathrm{Lat}}$ and $\mathrm{ER}_{\mathrm{Ax}}$ showed a strong negative correlation. $\mathrm{ER}_{\mathrm{Ax}}$ showed a strong positive correlation with RDW, while the contribution of $\mathrm{k}_{\mathrm{Lat}}$ was not significant. This finding is confirmed by a weak negative correlation between the ratio of $\mathrm{k}_{\mathrm{Lat}}$ and $\mathrm{ER}_{\mathrm{Ax}}$ with RDW. Furthermore, a moderate negative correlation was found between leaf area and the ratio of $\mathrm{k}_{\mathrm{Lat}}$ to $\mathrm{ER}_{\mathrm{Ax}}$. 
Table 1 Analysis of variance for root and shoot traits of CML444 and SC-Malawi as affected by desiccation stress induced by polyethylene glycol (PEG)

\begin{tabular}{|c|c|c|c|c|c|c|c|c|}
\hline ANOVA & $\mathrm{No}_{\mathrm{Ax}}$ & $\mathrm{ER}_{\mathrm{Ax}}\left(\mathrm{cm} \mathrm{day}{ }^{-1}\right)$ & $\mathrm{L}_{\operatorname{PrAx}}(\mathrm{cm})$ & $\mathrm{k}_{\text {Lat }}\left(\mathrm{cm} \mathrm{day}^{-1}\right)$ & $\mathrm{k}_{\mathrm{Lat}} \mathrm{ER}_{\mathrm{Ax}}$ & RDW (mg) & WP (-MPa) & $\mathrm{LA}\left(\mathrm{cm}^{2}\right)$ \\
\hline \multicolumn{9}{|l|}{ Significance level } \\
\hline Treatment & ns & $* *$ & ns & $*$ & ns & $*$ & $* * *$ & $* * *$ \\
\hline Genotype & ns & ns & ns & $*$ & ns & ns & $* * *$ & $*$ \\
\hline Treatment $\times$ genotype & ns & ns & ns & ns & $\mathrm{ns}$ & $\mathrm{ns}$ & ns & ns \\
\hline \multicolumn{9}{|l|}{ Treatment (\% PEG) } \\
\hline 0 & 4.8 & $6.26 \mathrm{a}$ & 181 & $0.478 \mathrm{a}$ & 0.08 & $63.3 \mathrm{a}$ & $0.139 \mathrm{a}$ & $27.8 \mathrm{a}$ \\
\hline 15 & 4.1 & 5.99 & 210 & 0.463 & 0.08 & 51.2 & $0.397 \mathrm{~b}$ & $15.6 \mathrm{~b}$ \\
\hline 20 & 3.5 & $4.46 \mathrm{~b}$ & 206 & $0.414 \mathrm{~b}$ & 0.13 & $38 \mathrm{~b}$ & $0.606 \mathrm{c}$ & $12.1 \mathrm{~b}$ \\
\hline \multicolumn{9}{|l|}{ Genotype } \\
\hline CML444 & 4.1 & 5.77 & 204 & $0.426 \mathrm{a}$ & 0.07 & 45.3 & $0.55 \mathrm{a}$ & $15.9 \mathrm{a}$ \\
\hline SC-Malawi & 4.2 & 5.36 & 193 & $0.478 \mathrm{~b}$ & 0.12 & 56.4 & $0.31 \mathrm{~b}$ & $21.1 \mathrm{~b}$ \\
\hline
\end{tabular}

Significance level and mean values for each treatment are displayed for the number of axile roots $\left(\mathrm{No}_{\mathrm{Ax}}\right)$, the elongation rate of axile roots $\left(E R_{\mathrm{Ax}}\right)$, the length of the primary axile root $\left(\mathrm{L}_{\mathrm{PrAx}}\right)$, the rate constant of lateral root elongation $\left(\mathrm{k}_{\mathrm{Lat}}\right)$, the ratio between $\mathrm{k}_{\mathrm{Lat}}$ and $\mathrm{ER}_{\mathrm{Ax}}\left(\mathrm{k}_{\mathrm{Lat}} /\right.$ $\mathrm{ER}_{\mathrm{Ax}}$ ), the root dry weight (RDW), water potential (WP) and leaf area (LA). Values followed by the same letter are not significantly different at $P=0.05$. Since no significant genotype-by-treatment interaction was observed mean values for genotypes across treatments are not shown

Table 2 Summary statistics of traits measured for the parental inbred lines (means) and their segregating RIL offspring

\begin{tabular}{|c|c|c|c|c|c|c|c|}
\hline Trait & CML444 & Malawi & Sig & Pop. Mean & First Quartile & Third Quartile & $h^{2 \mathrm{a}}$ \\
\hline $\mathrm{L}_{\mathrm{Ax}}(\mathrm{cm})$ & 54.5 & 42.9 & ns & 63.2 & 52.2 & 72.9 & 0.81 \\
\hline $\mathrm{No}_{\mathrm{Ax}}$ & 5.17 & 4.09 & ns & 5.08 & 4.51 & 5.54 & 0.69 \\
\hline $\mathrm{ER}_{\mathrm{Ax}}\left(\mathrm{cm} \mathrm{day}^{-1}\right)$ & 7.33 & 5.60 & ns & 8.11 & 6.72 & 9.40 & 0.8 \\
\hline $\mathrm{L}_{\operatorname{PrAx}}(\mathrm{cm})$ & 21.1 & 22.8 & ns & 23.1 & 21.0 & 34.3 & 0.81 \\
\hline $\mathrm{L}_{\text {Lat }}(\mathrm{cm})$ & 28.5 & 38.9 & ns & 43.4 & 31.6 & 51.2 & 0.88 \\
\hline $\mathrm{k}_{\text {Lat }}\left(\mathrm{cm} \mathrm{day}^{-1}\right)$ & 0.37 & 0.42 & $*$ & 0.387 & 0.363 & 0.413 & 0.73 \\
\hline $\mathrm{k}_{\mathrm{Lat}} \mathrm{ER}_{\mathrm{Ax}}$ & 0.0509 & 0.0756 & $*$ & 0.0500 & 0.0416 & 0.0569 & 0.83 \\
\hline RDW (mg) & 54.8 & 29.2 & ns & 42.5 & 37.2 & 46.4 & 0.87 \\
\hline LA $\left(\mathrm{cm}^{2}\right)$ & 16.4 & 17.9 & ns & 21.29 & 18.65 & 23.7 & 0.84 \\
\hline HKW (g) & 25.0 & 25.0 & na & 24.4 & 20.6 & 28.0 & na \\
\hline
\end{tabular}

Traits were axile root length $\left(\mathrm{L}_{\mathrm{Ax}}\right)$, the number of axile roots $\left(\mathrm{No}_{\mathrm{Ax}}\right)$, the elongation rate of axile roots $\left(\mathrm{ER}_{\mathrm{Ax}}\right)$, the length of the primary root $\left(\mathrm{L}_{\mathrm{PrAx}}\right)$, the rate constant of lateral root elongation $\left(\mathrm{k}_{\mathrm{Lat}}\right)$, the ratio between $\mathrm{k}_{\mathrm{Lat}}$ and $\mathrm{ER}_{\mathrm{Ax}}\left(\mathrm{k}_{\mathrm{Lat}} / \mathrm{ER}_{\mathrm{Ax}}\right)$, root dry weight $(\mathrm{RDW})$, leaf area $(\mathrm{LA})$ and hundred kernel weight (HKW)

na not available

* Significant differences $(P=0.05)$ between parents

${ }^{a}$ Mean-based heritability

\section{Detected QTLs}

All in all 12 QTLs were identified for four different root traits (Table 4): one for $\mathrm{L}_{\mathrm{PrAx}}$, three for $\mathrm{k}_{\mathrm{Lat}}$ (all of them with negative additivity), four for both $\mathrm{ER}_{\mathrm{Ax}}$ and $\mathrm{No}_{\mathrm{Ax}}$ and five for HKW. No QTL was detected for $\mathrm{k}_{\mathrm{Lat}} / \mathrm{ER}_{\mathrm{Ax}}$.

The genomic region in bins 2.03-2.05 affected general root vigor. Four QTLs for $\mathrm{No}_{\mathrm{Ax}}, \mathrm{HKW}, \mathrm{ER}_{\mathrm{Ax}}$ and $\mathrm{k}_{\mathrm{Lat}}$ positively collocated in bins 2.03-2.05. The allele of SCMalawi increased the trait values for $\mathrm{No}_{\mathrm{Ax}}, \mathrm{HKW}, \mathrm{ER}_{\mathrm{Ax}}$ and $\mathrm{k}_{\mathrm{Lat}}$ by $0.19,1.36 \mathrm{~g}, 0.48$ and $0.01 \mathrm{~cm}^{-1 a y}{ }^{-1}$, respectively. The fact that there was a QTL for HKW in this region indicates that root vigor was affected by seed reserves. Therefore, the QTL for root vigor may in fact be a seed vigor QTL, which affects root growth.

In addition to the QTL for root vigor, three QTLs were identified for $\mathrm{ER}_{\mathrm{Ax}}$ (Table 4). The presence of the CML444 allele altered $\mathrm{ER}_{\mathrm{Ax}}$ by $0.54 \mathrm{~cm} \mathrm{day}^{-1}$ (bin 1.03), $0.55 \mathrm{~cm} \mathrm{day}^{-1}$ (bin 1.08) and $-0.54 \mathrm{~cm} \mathrm{day}^{-1}$ (bin 7.03). Each of the QTLs in these three regions explained about 7.6\% of the phenotypic variance (PVE). Most QTLs identified for $\mathrm{ER}_{\mathrm{Ax}}$ collocated with QTLs for $\mathrm{No}_{\mathrm{Ax}}$, reinforcing the strong correlation between these traits.

QTLs only altering $\mathrm{k}_{\mathrm{Lat}}$ were identified in bins 1.01 and 8.01. Values for $\mathrm{k}_{\mathrm{Lat}}$ were increased by alleles derived from SC-Malawi. Trait values for $\mathrm{k}_{\mathrm{Lat}}$ were altered by -0.0093 
Table 3 Pearson's phenotypic correlation coefficients among traits measured in the RIL population: hundred kernel weight (HKW), leaf area (LA), root dry weight $(\mathrm{RDW})$, the constant of lateral root elongation $\left(\mathrm{k}_{\mathrm{Lat}}\right)$, the elongation rate of axile roots $\left(\mathrm{ER}_{\mathrm{Ax}}\right)$, the number of axile roots $\left(\mathrm{No}_{\mathrm{Ax}}\right)$ and the ratio between $\mathrm{k}_{\mathrm{Lat}}$ and $\mathrm{ER}_{\mathrm{Ax}}\left(\mathrm{k}_{\mathrm{Lat}} / \mathrm{ER}_{\mathrm{Ax}}\right)$ and the length of the primary root $\left(\mathrm{L}_{\mathrm{PrAx}}\right)$

\begin{tabular}{|c|c|c|c|c|c|c|c|c|c|}
\hline & LA & RDW & $\mathrm{k}_{\text {Lat }}$ & $\mathrm{ER}_{\mathrm{Ax}}$ & $\mathrm{No}_{\mathrm{Ax}}$ & $\mathrm{L}_{\text {Lat }}$ & $\mathrm{L}_{\mathrm{Ax}}$ & $\mathrm{k}_{\mathrm{Lat}} / \mathrm{ER}_{\mathrm{Ax}}$ & $\mathrm{L}_{\operatorname{PrAx}}$ \\
\hline HKW & $0.53 * * *$ & $0.21 *$ & $0.02 *$ & $0.42 * * *$ & $0.39 * * *$ & $0.23 * *$ & $0.42 * * *$ & $0.14 * * *$ & $0.00, \mathrm{~ns}$ \\
\hline LA & & $0.51 * * *$ & $0.12, \mathrm{~ns}$ & $0.51 * * *$ & $0.47 * * *$ & $0.43 * * *$ & $0.61 * * *$ & $-0.56 * * *$ & $0.15 * * *$ \\
\hline RDW & & & $0.14, \mathrm{~ns}$ & $0.52 * *$ & $0.42 * * *$ & $0.40 * * *$ & $0.56 * * *$ & $-0.45 * * *$ & $0.15 * * *$ \\
\hline $\mathrm{k}_{\text {Lat }}$ & & & & $0.38 * * *$ & $0.21 * *$ & $0.68 * * *$ & $0.38 * * *$ & 0.08. ns & $0.07 * * *$ \\
\hline $\mathrm{ER}_{\mathrm{Ax}}$ & & & & & $0.82 * * *$ & $0.53 * * *$ & $0.99 * * *$ & $-0.85 * * *$ & $0.18 * * *$ \\
\hline $\mathrm{No}_{\mathrm{Ax}}$ & & & & & & $0.34 * * *$ & $0.81 * * *$ & $-0.77 * * *$ & $0.12, \mathrm{~ns}$ \\
\hline $\mathrm{L}_{\text {Lat }}$ & & & & & & & $0.60 * * *$ & $-0.19 * * *$ & $0.28 * * *$ \\
\hline $\mathrm{k}_{\mathrm{Lat}} \mathrm{ER}_{\mathrm{Ax}}$ & & & & & & & & & $0.11 * * *$ \\
\hline
\end{tabular}

Correlation coefficients followed by $*, * *$, and $* * *$ are significant at $P=0.05,0.01$, and 0.001 , respectively

Table 4 QTLs (LOD > 2.6) involved in the expression of the number of axile roots $\left(\mathrm{No}_{\mathrm{Ax}}\right)$, the elongation rate of axile roots $\left(E R_{\mathrm{Ax}}\right)$, the length of the primary root $\left(\mathrm{L}_{\mathrm{PrAx}}\right)$, the rate constant of lateral root elongation $\left(\mathrm{k}_{\mathrm{Lat}}\right)$, the ratio between $\mathrm{k}_{\mathrm{Lat}}$ and $\mathrm{ER}_{\mathrm{Ax}}\left(\mathrm{k}_{\mathrm{Lat}} \mathrm{ER}_{\mathrm{Ax}}\right)$, root dry weight $(\mathrm{RDW})$, leaf area (LA) and hundred kernel weight (HKW)

\begin{tabular}{|c|c|c|c|c|c|c|c|c|c|}
\hline Trait & $\mathrm{Chr}$ & Marker & Mark & Bin & Peak & Interval & LOD & $\mathrm{ADD}$ & PVE \% \\
\hline $\mathrm{No}_{\mathrm{Ax}}(\mathrm{cm})$ & 1 & 3 & umc1041 & 1.01 & 45 & $23-53$ & 4.89 & 0.24 & 8.93 \\
\hline $\mathrm{No}_{\mathrm{Ax}}(\mathrm{cm})$ & 1 & 17 & umc128 & 1.08 & 219 & $214-231$ & 2.61 & 0.17 & 4.31 \\
\hline $\mathrm{No}_{\mathrm{Ax}}(\mathrm{cm})$ & 2 & 5 & $\operatorname{csu} 40$ & 2.03 & 100 & $88-114$ & 3.16 & -0.19 & 5.49 \\
\hline $\mathrm{No}_{\mathrm{Ax}}(\mathrm{cm})$ & 7 & 10 & bnl14.07 & 7.04 & 106 & $97-129$ & 4.97 & -0.26 & 10.1 \\
\hline $\mathrm{ER}_{\mathrm{Ax}}\left(\mathrm{cm} \mathrm{day}^{-1}\right)$ & 1 & 9 & bnlg439 & 1.03 & 108 & $98-130$ & 4.23 & 0.54 & 7.39 \\
\hline $\mathrm{ER}_{\mathrm{Ax}}\left(\mathrm{cm} \mathrm{day}{ }^{-1}\right)$ & 1 & 17 & umc128 & 1.08 & 219 & 214-231 & 4.53 & 0.55 & 7.81 \\
\hline $\mathrm{ER}_{\mathrm{Ax}}\left(\mathrm{cm} \mathrm{day}{ }^{-1}\right)$ & 2 & 7 & umc $8 \mathrm{~g}$ & 2.05 & 114 & $100-121$ & 3.43 & -0.48 & 5.83 \\
\hline $\mathrm{ER}_{\mathrm{Ax}}\left(\mathrm{cm} \mathrm{day}{ }^{-1}\right)$ & 7 & 9 & bnlg 1805 & 7.03 & 93 & $81-110$ & 3.26 & -0.54 & 7.46 \\
\hline $\mathrm{L}_{\operatorname{PrAx}}(\mathrm{cm})$ & 8 & 4 & umc103a & 8.02 & 63 & $51-78$ & 2.72 & -0.84 & 5.57 \\
\hline $\mathrm{k}_{\text {Lat }}\left(\mathrm{cm} \mathrm{day}{ }^{-1}\right)$ & 1 & 1 & phi056 & 1.01 & 10 & $0-20$ & 2.97 & -0.0093 & 5.15 \\
\hline $\mathrm{k}_{\text {Lat }}\left(\mathrm{cm} \mathrm{day}^{-1}\right)$ & 2 & 7 & umc8 $\mathrm{g}$ & 2.05 & 116 & $100-123$ & 3.81 & -0.011 & 7.21 \\
\hline $\mathrm{k}_{\text {Lat }}\left(\mathrm{cm} \mathrm{day}^{-1}\right)$ & 8 & 1 & npi114a & 8.01 & 0 & $0-14$ & 4.24 & -0.011 & 7.36 \\
\hline LA $\left(\mathrm{cm}^{2}\right)$ & 5 & 17 & umc104b & 5.08 & 244 & 228-244 & 3.06 & 1.01 & 6.09 \\
\hline LA $\left(\mathrm{cm}^{2}\right)$ & 6 & 6 & umc65a & 6.04 & 65 & $55-72$ & 3.80 & -1.10 & 7.24 \\
\hline HKW (g) & 1 & 24 & bnlg2331 & 1.11 & 347 & $330-360$ & 2.93 & 1.16 & 4.87 \\
\hline HKW (g) & 2 & 6 & umc135 & 2.04 & 102 & $90-114$ & 3.31 & -1.36 & 6.42 \\
\hline HKW (g) & 2 & 12 & csu154a & 2.07 & 162 & $155-167$ & 2.67 & -1.12 & 4.71 \\
\hline HKW (g) & 6 & 6 & umc65a & 6.04 & 56 & $43-68$ & 4.18 & -1.38 & 7.14 \\
\hline HKW (g) & 7 & 2 & umc1066 & 7.01 & 13 & $1-25$ & 6.45 & 1.91 & 12.7 \\
\hline
\end{tabular}

Chromosome number (Chr), marker number on the chromosome (Marker), marker name (Mark), chromosome segment (Bin), position of the peak in $\mathrm{cM}$ (Peak), 0.5 LOD support interval (Interval), LOD score at the peak (LOD), additive genetic effect of the CML444 allele on trait expression (ADD) and percentage of phenotypic variation explained by an individual QTL (PVE)

and $0.0111 \mathrm{~cm} \mathrm{day}^{-1}$, respectively for both QTLs at PVE of 5.1 and $7.4 \%$.

Collocation of QTLs for root traits with QTLs identified in the reproductive stage in the field

In order to get an idea of possible associations between the genetic control of seedling root traits and morpho-physiological traits measured in the same RIL population in several field experiments involving well-watered conditions and drought stress at flowering, the QTLs of the present study were compared with QTLs reported by Messmer (2006). Three genomic regions were identified on chromosomes 1, 2 and 7. The LOD support interval of the QTL for ER $\mathrm{Ax}_{\mathrm{x}}$ in bin 1.03 (near bnlg439) overlapped with those of QTLs in the most outstanding region identified by Messmer (2006) (Fig. 3). The latter comprises QTLs for grain yield and plant height in different environments, which suggested the presence of major genes regulating carbon-partitioning mechanisms, as well as QTLs for leaf greenness (SPAD-value) and 


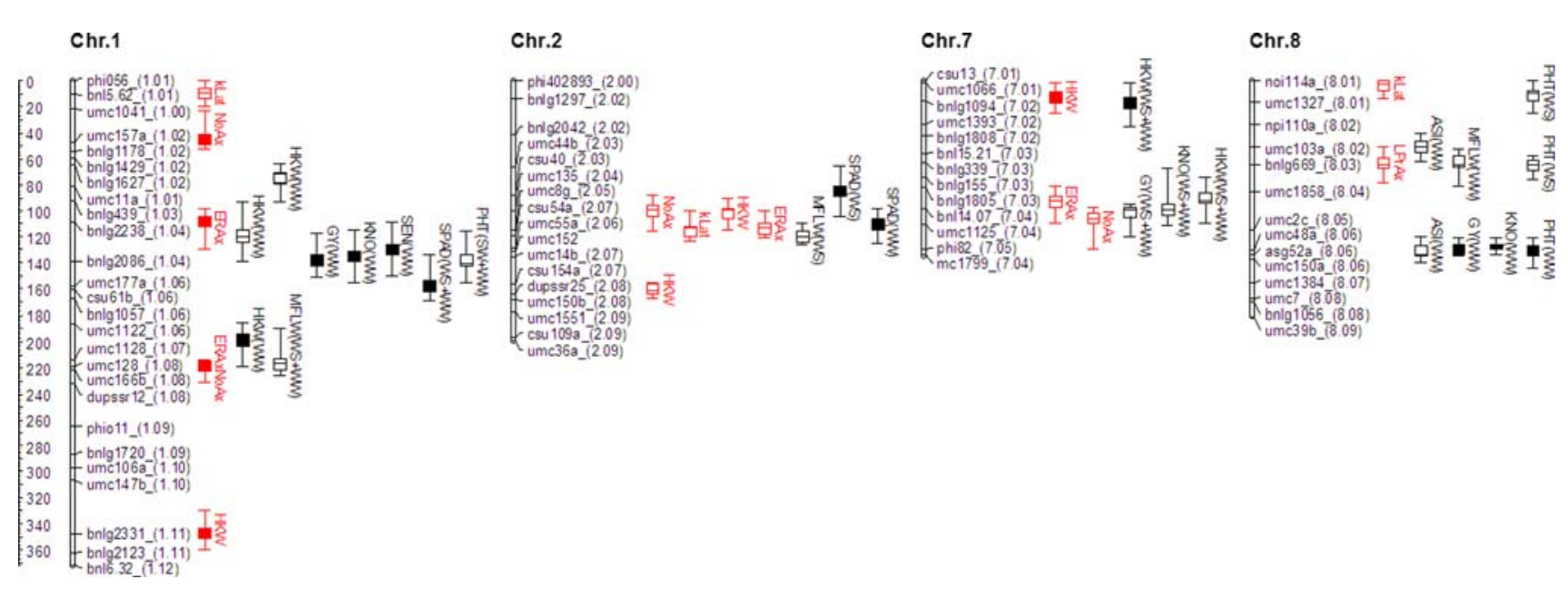

Fig. 3 Collocations of QTLs for seedling traits (red boxplots) with those detected by Messmer (2006) at the reproductive stage (black boxplots) under water stress (WS), well watered $(W W)$ or both $(\mathrm{WW}+\mathrm{WS})$. Seedling traits were the rate constant of lateral root elongation $\left(k_{L a t}\right)$, elongation rate of axile roots $\left(E_{R A x}\right)$, the number of axile roots $\left(N o_{A x}\right)$, the length of the primary $\operatorname{root}\left(L_{P r A x}\right)$ and the hundred kernel weight $(H K W)$. Traits at the reproductive stage were the time to male flowering $(M F L W)$, plant height $(P H T)$, relative

a visual score of plant senescence, mostly under wellwatered conditions. The alleles of CML444 contributed to an increase in $\mathrm{ER}_{\mathrm{Ax}}$, to higher leaf greenness and to either higher grain yield (under well-watered conditions) or a reduced plant height (under drought stress). The cluster of QTLs for root vigor on chromosome 2 (bin 2.03-2.05) collocated with a cluster of QTLs controlling the greenness of the ear leaf and the second leaf from the tassel at flowering in six field experiments with different levels of water availability. While the allele of CML444 decreased the phenotypic value of all concerned root traits in the present study (Table 4), it was associated with higher leaf greenness at flowering (Messmer 2006). The third cluster of collocating QTLs was located on chromosome 7 (bin 7.03-7.04), where the support intervals of QTLs for $\mathrm{No}_{\mathrm{Ax}}$ and $\mathrm{ER}_{\mathrm{Ax}}$ overlapped with those of QTLs for grain yield, kernel number and hundred kernel fresh weight, which were identified in a combined QTL analysis across seven experiments. The allele of CML444 at these QTLs decreased the phenotypic values of $\mathrm{No}_{\mathrm{Ax}}$ and $\mathrm{ER}_{\mathrm{Ax}}$ (Table 4) as well as those of the yield parameters (Messmer et al. 2009).

\section{Discussion}

Parental lines show similar responses to PEG-induced desiccation

For both genotypes the desiccation treatment caused a reduction in shoot and root growth except for the growth of chlorophyll content of the ear leaf and/or the second leaf from the tassel $(S P A D)$, visual senescence scoring $(S E N)$, kernel number $(K N O)$, hundred kernel weight $(H K W)$ and grain yield $(G Y)$. The boxes indicate intervals of $\pm 4 \mathrm{cM}$ around the peak of the QTL. Whiskers indicate the LOD support intervals. Filled and empty symbols represent positive and negative additive effects (CML444 allele)

the primary axile root $\left(\mathrm{L}_{\mathrm{PrAx}}\right)$. Apart from the lack of differences in response to desiccation among the parents, the stress treatment caused symptoms similar to those observed in vermiculite substrate with a low water potential; i.e. decreased LWP and LA (Sharp and Davies 1985) and decreased root elongation rates (Sharp et al. 2004). However, care must be taken when interpreting the results from desiccation experiments using osmolytes such as PEG. Although PEG with a high molecular weight was used in many studies to simulate the effect of drought on the root system (Lawlor 1970; Money 1989; van der Weele et al. 2000; Nayyar and Gupta 2006) and to differentiate among genotypes (Sanguineti et al. 2006), it should be kept in mind that drought stress in the field does not affect the soil water potential alone. For example, drought goes along with changes in the mechanical resistance and soil-grown plants respond to drought in a complex way. However, PEG may be used for a first and rapid screening for desiccation tolerance.

The parents did not differ in their response to PEG and in their desiccation tolerance, but they differed strongly in root morphology, irrespective of the desiccation treatment. This observation is in line with other studies, which emphasized that constitutive rather than adaptive differences are key factors for drought adaptation of the root system in cereals: Hund et al. (2009a, for maize) and Kato et al. (2006, for rice) reported constitutive differences among genotypes for total root length and the amount of roots at depths below $50 \mathrm{~cm}$. Moreover a constitutive QTL controlling leaf ABA (root-ABAl) content under 
water-stressed and well watered conditions with effects on root architecture (number, angles, branching, diameter and weight) (Giuliani et al. 2005) ultimately affecting root lodging and grain yield (Landi et al. 2007) was identified in bins 2.04 .

Differences in $\mathrm{k}_{\mathrm{Lat}}$ and $\mathrm{ER}_{\mathrm{Ax}}$ may be explained by differences in the organization of the embryonic root system

We reported differences in root growth rates, rather than differences in root length at a given time to avoid errors due to differences in germination as pointed out by Hund et al. (2009b). At the seedling stage the variation in the length of the lateral roots that is due to differences in germination can be large. Initially, the entity of lateral roots per genotype elongates exponentially unless the first lateral roots cease growing. The growth constant $\mathrm{k}_{\text {Lat }}$ serves as an integrative measure for the potential final length and linear density of the lateral roots (Hund et al. 2009b). However, the separation into axile and lateral roots disregards the organization of the embryonic root system. Primary roots show considerable genetic variation with respect to the length of individual lateral roots. Depending on the genotype, the lengths of the longest lateral roots may vary between 2 and $17 \mathrm{~cm}$ at the $\mathrm{V} 2$ stage (Hund et al. 2007), while those of the seminal roots are usually short and in the range of $3 \mathrm{~cm}$ (McCully 1999; Hund et al. 2007). Hund et al. (2007) classified genotypes according to the organization of the embryonic root systems as homogeneous (similar primary and seminal roots) and heterogeneous (lateral roots of the primary root generally longer than the lateral roots of the seminal roots). A similar morphology was also demonstrated for two RILs used in the present study. The RILs differed for $\mathrm{k}_{\text {Lat }}$ because of differences in the final length and linear density of the primary lateral roots (Hund et al. 2009b). Apart from a direct genetic control of lateral root initiation and growth, more seed reserves may explain the more intense branching of the primary root as pointed out by Enns et al. (2006). These authors observed that the length and linear density of the population of primary lateral roots (branch roots) of about the first $8 \mathrm{~cm}$ proximal to the seed strongly depended on seed reserves. Indeed, the correlations between HKW and root traits as well as leaf area indicate the influence of the seed weight on early vigor. However, lateral roots and the $\mathrm{k}_{\mathrm{Lat}} / \mathrm{ER}_{\mathrm{Ax}}$ ratio were hardly correlated $(r<0.2)$ with $\mathrm{HKW}$, which indicates that root morphology as such was little affected by seed reserves. Nevertheless it should be considered that the collocating QTLs controlling HKW, axile and lateral root traits (bins 2.04-2.05) indicate a certain genetic correspondence.
The relationship between axile and lateral roots may be indicative for rooting depth

CML444 formed a root system with constitutively less lateral roots and in relation to the entire root length more axile roots than SC-Malawi, as indicated by a higher $\mathrm{ER}_{\mathrm{Ax}}$ (ns), $\mathrm{L}_{\operatorname{PrAx}}$ (ns) and a lower $\mathrm{k}_{\mathrm{Lat}}$. Root elongation depends on carbon availability within the plant (Pritchard and Rogers 2000). Assuming an ample nutrient supply in the soil, the growth of axile roots may be increased in a root system with fewer lateral roots, leading to deeper rooting. This hypothesis is supported by findings of Hund et al. (2009a) who showed that CML444 had a root system with fewer lateral roots in the topsoil but with thicker, deepreaching axile roots, compared to SC-Malawi. As a consequence CML444 took up more water than SC-Malawi (Hund et al. 2009a). There are other studies supporting the hypothesis that the relationship between axile and lateral roots may be a critical trigger for the resource allocation within the root system leading to increased rooting depths. Maize genotypes with a reduced development of crown (adventitious) and lateral roots at the seedling stage (Bruce et al. 2002) and with a smaller amount of roots in the top $50 \mathrm{~cm}$ of the soil profile (Bolaños et al. 1993) extract less water from the topsoil (Campos et al. 2004) and are better adapted to drought conditions. This is in accordance with the model discussed by Giuliani et al. (2005) showing that a QTL for leaf-ABA content constitutively controlled root architecture irrespective of water availability. This gives rise to the important question whether the root morphology in growth pouches can be predictive for the performance under drought at later stages of development.

QTLs for seedling root growth are associated with QTLs for grain yield in the field

The allelic effects at QTLs in the two genomic regions where collocating QTLs for seedling root traits and yield parameters in the field were observed are in agreement with the hypothesis that the growth of axile roots (at the seedling stage) is positively associated with rooting depth and, potentially, with drought resistance in the field (at flowering). The increase in the elongation of axile roots provoked by the CML444 allele at the respective QTL in bin 1.03-04 coincided with a positive effect on grain yield in an optimal growing environment. Under suboptimal conditions in the field, when the carbon allocation pattern within the plant seemed altered and the overall carbon assimilation was reduced, the CML444 allele provoked a reduction in plant growth. It is likely that the CML444 allele and the collocating QTL for $\mathrm{ER}_{\mathrm{Ax}}$ reduced the elongation rate of axile roots in the field. This would explain why the QTL effect on grain yield disappeared in these situations. Moreover 
Table 5 Comparison of root trait QTLs found in this study with those published in literature

\begin{tabular}{|c|c|c|c|c|c|}
\hline Bin & Marker & Pioneer & Trait & Population & Reference \\
\hline 1.02 & umc157a & 29.8 & $\mathrm{No}_{A x}$ & CML444 $\times$ SC-Malawi & \\
\hline 1.02 & bnlg1014 & 20.7 & $\mathrm{rtcs}$ & & Hochholdinger and Feix (1998) \\
\hline 1.02 & bnlg1429 & 34.5 & $\mathrm{rtcs}$ & & and Taromina et al. (2007) \\
\hline 1.03 & bnlg439 & 61 & $\mathrm{ER}_{\mathrm{Ax}} ; \mathrm{No}_{\mathrm{Ax}}$ & CML444 × SC-Malawi & \\
\hline 1.03 & bnlg2238 & 69 & $\mathrm{ER}_{\mathrm{Ax}} ; \mathrm{No}_{\mathrm{Ax}}$ & CML444 × SC-Malawi & \\
\hline 1.03 & bnlg2086 & 101 & $\mathrm{ER}_{\mathrm{Ax}} ; \mathrm{No}_{\mathrm{Ax}}$ & CML444 × SC-Malawi & \\
\hline 1.03 & bnlg176 & 51 & $\begin{array}{l}\text { Length and weight } \\
\text { of the primary root }\end{array}$ & Lo964 × Lo1016 & Tuberosa et al. (2002) \\
\hline 1.03 & umc11a & 53 & Leaf abscisic acid content & Os420 $\times$ IABO78 & Tuberosa et al. (1998) \\
\hline 1.03 & umc11a & 53 & $\begin{array}{l}\text { Primary root weight, } \\
\text { seminal axile root length }\end{array}$ & Lo964 × Lo1016 & \\
\hline 1.03 & asg45 & 74 & & & Hund et al. (2004) \\
\hline 1.03 & bnlg 1866 & 60 & Axile root length & $\mathrm{Z} 3 \times 87-1$ & \\
\hline 1.03 & bnlg2180 & 64 & & & Liu et al. (2008) \\
\hline 1.08 & umc128 & 187 & $\mathrm{ER}_{\mathrm{Ax}} ; \mathrm{No}_{\mathrm{Ax}}$ & CML444 × SC-Malawi & \\
\hline 1.08 & umc166b & 167 & $\mathrm{ER}_{\mathrm{Ax}} ; \mathrm{No}_{\mathrm{Ax}}$ & CML444 × SC-Malawi & \\
\hline 1.08 & dupssr12 & 160 & $\mathrm{ER}_{\mathrm{Ax}} ; \mathrm{No}_{\mathrm{Ax}}$ & CML444 × SC-Malawi & \\
\hline 1.08 & gsy 282 & 160 & Whole plant nitrogen uptake efficiency & Io $\times \mathrm{F} 2$ & \\
\hline 1.08 & umc83a & 174 & Whole plant nitrogen uptake efficiency & Io $\times$ F2 & Gallais and Hirel (2004) \\
\hline 1.08 & php20644 & 137 & Length and weight of the primary root & Lo964 × Lo1016 & Tuberosa et al. (2002) \\
\hline 1.08 & umc128 & 187 & Leaf abscisic acid content & Os420 × IABO78 & Tuberosa et al. (1998) \\
\hline
\end{tabular}

Position of potential candidate genes and QTLs in relation to the QTLs detected in the present study and to common SSR markers from the CML444 $\times$ SC-Malawi population and from the Pioneer composite 1999 map

and as outlined below, this genomic region seems to be generally important for the genetic control of both shoot and root development.

The corresponding signs of the additive effects at the collocating QTLs on chromosome seven further suggest that the genetic control of root growth may be linked with the reproductive behavior in the plant material studied. However, the QTL effect on grain yield and kernel number has to be interpreted with care, as it was not significant in the analyses of individual experiments (data not shown).

Several genomic regions control the same root traits in other genetic backgrounds

We identified a QTL for $\mathrm{No}_{\mathrm{Ax}}$ in the vicinity of the anchor marker umc157a (at $29.8 \mathrm{cM}$ on the 1999 Pioneer composite map). The rtcs mutant (Hetz et al. 1996) lacking crown and seminal roots maps to the same region (Table 5). The rtcs locus has been cloned and is relevant for the activation of auxin-responsive genes involved in the initiation of root formation (Taromina et al. 2007). It is therefore possible that the QTL detected for $\mathrm{No}_{\mathrm{Ax}}$ is a QTL involved in hormone physiology determining the number of axile roots.
The QTL identified for $\mathrm{ER}_{\mathrm{Ax}}$ in bin 1.03 collocated with QTLs identified in the Lo964 $\times$ Lo1016 population for the weight of the seminal roots of hydroponically-grown seedlings and for grain yield in the field (Tuberosa et al. 2002; Hochholdinger and Tuberosa 2009) and the number and length of the seminal roots (Hund et al. 2004). Thus, in two independent populations and in several QTL studies, seminal root numbers and length were controlled by this locus. The QTL identified for $\mathrm{ER}_{\mathrm{Ax}}$ in bin 1.08 collocated with QTLs for leaf ABA-content (Tuberosa et al. 1998), the weight of the seminal roots (Tuberosa et al. 2002), N-uptake (Gallais and Hirel 2004) and the average axile root length under high and low $\mathrm{N}$ (Liu et al. 2008). Overall these collocations indicate that the QTLs identified for $\mathrm{ER}_{\mathrm{Ax}}$ in bins 1.03 and 1.08 are very important for axile root growth and underline the importance of a well developed root system for sufficient uptake of water and $\mathrm{N}$, and for yield formation. Furthermore the QTL for $\mathrm{k}_{\mathrm{Lat}}$ in bin 2.05 identified in the present study, collocated with a QTL for the number and length of lateral roots under conditions of high and low phosphorous in the IBM population (Zhu et al. 2005b). In summary, QTLs for root mass and axile root growth were found at the same position in several populations. Therefore it may be anticipated that the 
identified QTLs revealed a common genetic basis of (axile) root growth, $\mathrm{N}$-acquisition and ABA-homeostasis.

Although growth rates of axile and lateral roots were affected by several QTLs, these explained only a small proportion of the observed phenotypic variance. None of the seven QTLs identified for $\mathrm{ER}_{\mathrm{Ax}}$ and $\mathrm{k}_{\mathrm{Lat}}$ explained more than 7\% PVE. Therefore, it is likely that $\mathrm{ER}_{\mathrm{Ax}}$ and $\mathrm{k}_{\text {Lat }}$ are controlled by many other loci, probably with lower PVE values, which were not identified in the present study.

\section{Conclusion}

Both lines, CML444 and SC-Malawi responded equally to desiccation stress induced by PEG-8000. CML444 formed a root system with less lateral roots and more axile roots in proportion to the entire root system than SC-Malawi, irrespective of the PEG concentration. These differences indicate that the superior resistance of CML444 to drought stress at flowering might be partially due to such an architecture of the root system, which helps avoiding desiccation. The collocation of QTLs for axile root traits in bins 1.03-1.04 and 7.03-7.04 with QTLs for yield components is in favor of this hypothesis. Considering the breeding history of the two parental lines, the differences in their early root morphology may partly be the results of selection for drought tolerance at flowering.

The correspondence of QTLs for axile root traits in bins 1.02-1.03 and 1.08 and QTLs for lateral root traits in bins 2.04-2.07 in several mapping populations suggests the presence of genes in controlling root growth in a wide range of genetic backgrounds.

Acknowledgments The authors would like to thank Dr. Yunbi Xu for supplying the mapping population, Susanne Hochmann and David Brändli for their technical assistance, Jann Röder for programming the scanning software and Cairsty Grassie for linguistic corrections on the manuscript. We would also like to thank two anonymous reviewers for their valuable comments for the improvement of the manuscript. This study was supported by the Generation Challenge Programme (Project 15)

\section{References}

Basten CJ, Weir BS, Zeng ZB (2002) QTL CARTOGRAPHER: a reference manual and tutorial for QTL mapping. Department of Statistics. North Carolina State University

Blum A (1985) Breeding crop varieties for stress environments. Crc Rev Plant Sci 2:199-238

Bolaños J, Edmeades GO, Martinez L (1993) Eight cycles of selection for drought tolerance in lowland tropical maize III. Responses in drought-adaptive physiological and morphological traits. Field Crops Res 31:269-286

Bruce WB, Edmeades GO, Baker TC (2002) Molecular and physiological approaches to maize improvement for drought tolerance. J Exp Bot 53:13-25
Butler D (2006) asreml: asreml() fits the linear mixed mode. $\mathrm{R}$ package version 2.00

Campos H, Cooper A, Habben JE, Edmeades GO, Schussler JR (2004) Improving drought tolerance in maize: a view from industry. Field Crops Res 90:19-34

Edmeades GO, Bolanos J, Chapman SC, Lafitte HR, Banziger M (1999) Selection improves drought tolerance in tropical maize populations: I. Gains in biomass, grain yield, and harvest index. Crop Sci 39:1306-1315

Enns LC, McCully ME, Canny MJ (2006) Branch roots of young maize seedlings, their production, growth, and phloem supply from the primary root. Funct Plant Biol 33:391-399

Fischer RA, Turner NC (1978) Plant productivity in arid and semiarid zones. Annu Rev Plant Physiol Plant Mol Biol 29:277-317

Fuad-Hassan A, Tardieu F, Turc O (2008) Drought-induced changes in anthesis-silking interval are related to silk expansion: a spatio-temporal growth analysis in maize plants subjected to soil water deficit. Plant Cell Environ 31:1349-1360

Gallais A, Hirel B (2004) An approach to the genetics of nitrogen use efficiency in maize. J Exp Bot 55:295-306

Giuliani S, Sanguineti MC, Tuberosa R, Bellotti M, Salvi S, Landi P (2005) Root-ABA1, a major constitutive QTL, affects maize root architecture and leaf $\mathrm{ABA}$ concentration at different water regimes. J Exp Bot 56:2061-2070

Hetz W, Hochholdinger F, Schwall M, Feix G (1996) Isolation and characterisation of rtcs, a mutant deficient in the formation of nodal roots. Plant J 10:845-857

Hochholdinger F, Feix G (1998) Early post-embryonic root formation is specifically affected in the maize mutant lrtl. Plant J 16:247255

Hochholdinger F, Tuberosa R (2009) Genetic and genomic dissection of maize root development and architecture. Curr Opin Plant Biol 12:172-177

Hund A, Frachboud Y, Soldati A, Frascaroli E, Salvi S, Stamp P (2004) QTL controlling root and shoot traits of maize seedlings under cold stress. Theor Appl Genet 109:618-629

Hund A, Richner W, Soldati A, Fracheboud Y, Stamp P (2007) Root morphology and photosynthetic performance of maize inbred lines at low temperature. Eur J Agron 27:52-61

Hund A, Ruta N, Liedgens M (2009a) Rooting depth and water use efficiency of tropical maize inbred lines, differing in drought tolerance. Plant Soil 318:311-325

Hund A, Trachsel S, Stamp P (2009b) Growth of axile and lateral roots of maize: I development of a phenotyping platform. Plant Soil. doi:10.1007/s11104-009-9984-2

Kato Y, Abe J, Kamoshita A, Yamagishi J (2006) Genotypic variation in root growth angle in rice (Oryza sativa L.) and its association with deep root development in upland fields with different water regimes. Plant Soil 287:117-129

Lagerwererff J, Eagle HE, Ogata G (1961) Control of osmotic pressure of culture solutions with polyethylene glycol. Science 133:1486-1487

Landi P, Sanguineti MC, Liu C, Li Y, Wang TY, Giuliani S, Bellotti M, Salvi S, Tuberosa R (2007) Root-ABA1 QTL affects root lodging, grain yield, and other agronomic traits in maize grown under well-watered and water-stressed conditions. J Exp Bot $58: 319-326$

Lawlor DW (1970) Absorption of polyethylene glycols by plants and their effects on plant growth. New Phytol 69:501-513

Lebreton C, Lazic Jancic V, Steed A, Pekic S, Quarrie SA (1995) Identification of QTL for drought responses in maize and their use in testing causal relationships between traits. J Exp Bot 46:853-865

Liu JC, Li JS, Chen FJ, Zhang FS, Ren TH, Zhuang ZJ, Mi GH (2008) Mapping QTLs for root traits under different nitrate levels at the seedling stage in maize (Zea mays L.). Plant Soil 305:253-265 
Lorens GF, Bennett JM, Loggale LB (1987) Differences in drought resistance between 2 corn hybrids.1. Water relations and root length density. Agr J 79:802-807

Ludlow MM, Muchow RC (1990) A critical-evaluation of traits for improving crop yields in water-limited environments. Adv Agr 43:107-153

McCully ME (1999) Roots in soil: unearthing the complexities of roots and their rhizospheres. Annu Rev Plant Physiol Plant Mol Biol 50:695-718

Messmer R (2006) The genetic dissection of key factors involved in the drought tolerance of tropical maize (Zea mays L.). Diss. ETH No. 16695, Zurich, Switzerland. http://e-collection.ethbib.ethz. $\mathrm{ch} /$ show?type $=$ diss \&nr $=16695$

Messmer R, Fracheboud Y, Banziger M, Vargas M, Stamp P, Ribaut JM (2009) Drought stress and tropical maize: QTL-by-environment interactions and stability of QTLs across environments for yield components and secondary traits. Theor Appl Genet 119:913-930

Money NP (1989) Osmotic-pressure of aqueous polyethylene glycols-relationship between molecular-weight and vapor-pressure deficit. Plant Physiol 91:766-769

Nayyar H, Gupta D (2006) Differential sensitivity of C-3 and C-4 plants to water deficit stress: association with oxidative stress and antioxidants. Env Exp Bot 58:106-113

Oertli JJ (1985) The response of plant-cells to different forms of moisture stress. J Plant Physiol 121:295-300

Paponov IA, Sambo P, Erley GSA, Presterl T, Geiger HH, Engels C (2005) Grain yield and kernel weight of two maize genotypes differing in nitrogen use efficiency at various levels of nitrogen and carbohydrate availability during flowering and grain filling. Plant Soil 272:111-123

Price AH, Steele KA, Moore BJ, Jones RGW (2002) Upland rice grown in soil-filled chambers and exposed to contrasting waterdeficit regimes II. Mapping quantitative trait loci for root morphology and distribution. Field Crops Res 76:25-43

Pritchard SG, Rogers HH (2000) Spatial and temporal deployment of crop roots in CO2-enriched environments. New Phytol 147:55-71

Rajcan I, Tollenaar M (1999) Source: sink ratio and leaf senescence in maize: II. Nitrogen metabolism during grain filling. Field Crops Res 60:255-265

R Development Core Team (2004) R: A language and environment for statistical computing. http://www.R-project.org. R Foundation for Statistical Computing, Vienna, Austria

Ribaut JM, Ragot M (2007) Marker-assisted selection to improve drought adaptation in maize: the backcross approach, perspectives, limitations, and alternatives. J Exp Bot 58:351-360

Ribaut JM, Betràn FJ, Monneveux P, Setter T (2008) Drought tolerance in maize. In: Hake SC, Bennetzen JL (eds) Hand book of maize: its biology. Springer, Netherlands, pp 311-344

Sanguineti MC, Duvick DN, Smith S, Landi P, Tuberosa R (2006) Effects of long-term selection on seedling traits and ABA accumulation in commercial maize hybrids. Maydica 51:329_ 338
Scholander PF, Bradstreet ED, Hemmingsen EA (1965) Sap pressure in vascular plants. Science 148:339-346

Sharp RE, Davies WJ (1985) Root-growth and water-uptake by maize plants in drying soil. J Exp Bot 36:1441-1456

Sharp RE, Poroyko V, Hejlek LG, Spollen WG, Springer GK, Bohnert HJ, Nguyen HT (2004) Root growth maintenance during water deficits: physiology to functional genomics. J Exp Bot 55:2343-2351

Shen L, Courtois B, McNally KL, Robin S, Li Z (2001) Evaluation of near-isogenic lines of rice introgressed with QTLs for root depth through marker-aided selection. Theor Appl Genet 103:75-83

Steele KA, Price AH, Shashidhar HE, Witcombe JR (2006) Markerassisted selection to introgress rice QTLs controlling root traits into an Indian upland rice variety. Theor Appl Genet 112:208 221

Steudle E (2000) Water uptake by roots: effects of water deficit. J Exp Bot 51:1531-1542

Taiz L, Zeiger E, Taiz L, Zeiger E (2002) Plant physiology, 3rd edn, vol I-xxvi. pp 1-690

Taromina G, Sauer M, Stauffer JL, Multani D, Niu X, Sakai H, Hochholdinger F (2007) The maize (Zea mays L.) RTCS gene encodes a LOB domain protein that is a key regulator of embryonic seminal and post-embryonic shoot-borne root initiation. Plant J 50:649-659

Tuberosa R, Sanguineti MC, Landi P, Salvi S, Casarini E, Conti S (1998) RFLP mapping of quantitative trait loci controlling abscisic acid concentration in leaves of drought stressed maize (Zea mays L.)

Tuberosa R, Salvi S, Sanguineti MC, Landi P, Maccaferri M, Conti S (2002) Mapping QTLs regulating morpho-physiological traits and yield: case studies, shortcomings and perspectives in drought-stressed maize. Ann Bot 89:941-963

van der Weele CM, Spollen WG, Sharp RE, Baskin TI (2000) Growth of Arabidopsis thaliana seedlings under water deficit studied by control of water potential in nutrient-agar media. J Exp Bot 51:1555-1562

Verslues PA, Agarwal M, Katiyar-Agarwal S, Zhu J, Zhu JK (2006) Methods and concepts in quantifying resistance to drought, salt and freezing, abiotic stresses that affect plant water status. Plant J 45:523-539

Wan CG, Xu WW, Sosebee RE, Machado S, Archer T (2000) Hydraulic lift in drought-tolerant and -susceptible maize hybrids. Plant Soil 219:117-126

Wang GL, Kang MS, Moreno O (1999) Genetic analyses of grainfilling rate and duration in maize. Field Crops Res 61:211-222

Zhu JM, Kaeppler SM, Lynch JP (2005a) Mapping of QTL controlling root hair length in maize (Zea mays L.) under phosphorus deficiency. Plant Soil 270:299-310

Zhu JM, Kaeppler SM, Lynch JP (2005b) Mapping of QTLs for lateral root branching and length in maize (Zea mays L.) under differential phosphorus supply. Theor Appl Genet 111:688-695 